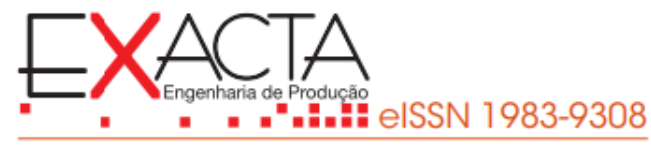

\title{
DESENVOLVIMENTO DE PRODUTO: UMA APLICAÇÃO NA ELABORAÇÃO DE UM APLICATIVO PARA CÁLCULO DE MATERIAL NA PRODUÇÃO DE CONCRETO
}

\section{PRODUCT DEVELOPMENT: AN APPLICATION IN THE DESIGN OF AN APPLICATION FOR CALCULATION OF MATERIAL IN CONCRETE PRODUCTION}

Recebido em: 14 dez. 2019

Aprovado em: 15 jun. 2020

Versão do autor aceita publicada online: 15 jun. 2020

Publicado online: 19 maio 2021

\section{Como citar esse artigo - American Psychological Association (APA):}

Sampaio, P. S., Gayer, J. A. C. A., Tamachiro, T. S. O., Oliveira, F. R., \& Marques, M. A. M. (2021, out./dez.). Desenvolvimento de produto: uma aplicação na elaboração de um aplicativo para cálculo de material na produção de concreto. Exacta. 19(4), 805-816.

https://doi.org/10.5585/exactaep.2021.14741.

Submeta seu artigo para este periódico $\beta$

Dados Crossmark 


\title{
DESENVOLVIMENTO DE PRODUTO: UMA APLICAÇÃO NA ELABORAÇÃO DE UM APLICATIVO PARA CÁLCULO DE MATERIAL NA PRODUÇÃO DE CONCRETO
}

\author{
PRODUCT DEVELOPMENT: AN APPLICATION IN THE DESIGN OF AN APPLICATION \\ FOR CALCULATION OF MATERIAL IN CONCRETE PRODUCTION
}

\author{
Daula Souza Sampaio ${ }^{1}$ \\ iD Jéssika Alvares Coppi Arruda Gayer \\ iD Thiago Shoji Obi Tamachiro ${ }^{3}$ \\ iD Fernanda Robes de Oliveira ${ }^{4}$ \\ Marcos Augusto Mendes Marques
}

${ }^{1}$ Especialização em Engenharia de Produção Centro Universitário Internacional - UNINTER Ribeirão Preto, São Paulo - Brasil. paula.s.s@bol.com.br

${ }^{2}$ Mestre em Engenharia de Produção UFPR - Universidade Federal do Paraná. Curitiba, Paraná - Brasil. jessika.ac@hotmail.com

${ }^{3}$ Mestre em Engenharia de Produção UFPR - Universidade Federal do Paraná. Curitiba, Paraná - Brasil. thiagotamachiro@gmail.com

${ }^{4}$ Mestre em Engenharia de Produção UFPR - Universidade Federal do Paraná. Curitiba, Paraná - Brasil.

fer.robes@gmail.com

${ }^{5}$ Doutor em Métodos Numéricos em Engenharia UFPR - Universidade Federal do Paraná. Curitiba, Paraná - Brasil. marquesammarcos@gmail.com

Recebido em: 14 dez. 2019

Aprovado em: 15 jun. 2020
Resumo: No Brasil, uma solução construtiva largamente empregada é o concreto armado, devido sua versatilidade, adaptabilidade, facilidade e técnica disseminada há muito tempo por todo país, porém uma dificuldade encontrada nas pequenas e médias obras é a quantificação de materiais para produzi-lo. Infelizmente, devido à falta de informação técnica é comum o desperdício ou falta dos materiais necessários (areia, brita e cimento). Surgiu, então, a ideia de criar uma ferramenta para calcular a quantidade dos materiais, proporcionando a redução de custo e impacto ambiental. O trabalho apresenta o processo de desenvolvimento de produto, no caso, um aplicativo para celulares com sistema operacional Android, desenvolvido a partir das três macro etapas e suas subdivisões: pré-desenvolvimento, desenvolvimento (a qual abrange o projeto informacional, projeto detalhado e lançamento do produto) e pós-desenvolvimento (processo de monitorização do produto). Também foi empregada a ferramenta para qualidade: Desdobramento da função qualidade (QFD), método de tradução dos requisitos do consumidor em características de qualidade para o produto, afetando diretamente a qualidade total do produto. Como resultado, o desenvolvimento do aplicativo obteve respostas positivas por parte dos usuários, por ser uma ferramenta fácil e rápida para mensuração de materiais necessários para obtenção de concreto.

Palavras-chave: Desenvolvimento de produto. Aplicativo para celular. Cálculo de quantidade de material para concreto.

Abstract: In Brazil, a constructive solution widely used or reinforced concrete, due to its versatility, adaptability, ease and widespread technique, for a long time throughout the country, but one difficulty found in small and media media is the quantification of materials for production. Unfortunately, due to the lack of common technical information or waste or lack of necessary materials (sand, gravel and cement). Then, an idea arose to create a tool to calculate the amount of materials, reduce cost reduction and environmental impact. The work presents the product development process, in this case, an application for cell phones with Android operating system, developed from three macro steps and its subdivisions: predevelopment, development (which is the information project, detailed project and product launch) and post-development (product monitoring process). A tool for quality was also employed: Deployment of the quality function (QFD), a method of translating consumer requirements into quality resources for the product, directly affecting the total quality of the product. As a result, the development of the application answers positive questions from users, as it is an easy and quick tool for measuring materials used for concrete use.

Keywords: Product development. Mobile app. Calculation of quantity of material for concrete. 
1 Introdução

O concreto é resultante da mistura de agregados (areia, brita) com cimento e água, além disso, podem-se acrescentar aditivos químicos e minerais para alterar algumas de suas características, bem como, a sua adaptabilidade a qualquer forma estrutural e fácil manejo (Giongo, 2007).

O sistema construtivo mais utilizado no Brasil é o concreto armado, sua hegemonia se dá pelo fato de ter sido introduzido há quase cem anos com enorme aceitação, tanto por parte dos engenheiros e arquitetos, quanto nas instituições de ensino que enfatizaram a sua utilização, bem como pelo fortalecimento da indústria de cimento que vem dos incentivos proporcionados pelo governo (Santos, 2008)

A Indústria de Construção Civil (ICC) consome uma grande quantidade de material, tanto em quantidade quanto diversidade. Tal diversidade, de quantidade e materiais aliados às peculiaridades do setor, traz uma dificuldade em comum que, independente do porte da obra, é a quantificação e especificação de material (Souza, 2004). Uma das maiores dificuldades é especificar a quantidade de areia, brita e cimento para formar o concreto na obra (Barboza \& Bastos, 2008).

Em obras de pequeno-médio porte e reformas em geral, a quantificação e a especificação do material ficam muitas vezes por conta do pedreiro ou lojista, sendo que possuem um conhecimento empírico, frequentemente não acertam a quantidade correta, ocasionando atrasos, tumultos ou sobras na obra (Barboza \& Bastos, 2008). Além disso, o fluxo de informações entre empreiteiros e subcontratados em geral é ruim, devido à baixa transparência, troca inadequada de informações e comunicação limitada (Dallasega et al., 2018).

Segundo Barboza e Bastos (2008), diante da falta de informação técnica a quantificação correta de material para elaboração de concreto, se faz majoritariamente de forma empírica, sendo permissível de erros. Portanto, existe relevância em desenvolver uma ferramenta que possa auxiliar no processo de criação do concreto, já que a ferramenta pode ser utilizada desde construtores, engenheiros, lojista da construção civil e, até mesmo, o proprietário da obra, permitindo minimizar o excesso/falta de materiais, reduzindo custos e possíveis resíduos.

É importante salientar que na preparação da mistura do concreto, as características de qualidade são formadas, e determinam em grande medida a qualidade e desempenho nas estruturas de edifícios. No caso de baixa uniformidade, pode haver um consumo excessivo de cimento, resultando em maior consumo de materiais e aumento de custo de construção (Judina, 2020).

Em uma crescente demanda por economia de recursos e maior produtividade em todos os processos de construção, impulsiona a busca por soluções mais eficientes e sustentáveis (de Carvalho et al., 2019). 
Diante deste contexto, o objetivo deste trabalho foi desenvolver uma ferramenta de fácil uso, tanto para profissionais da área de construção como leigos, para auxílio no cálculo de quantidade de material necessário para produção de concreto, combatendo o desperdício e/ou sobra destes.

Uma ferramenta para cálculo de quantidade de materiais para produção de concreto facilitaria o cotidiano de engenheiros, mestres-de-obras, pedreiros, atendentes de lojas de materiais de construção e leigos que estão reformando e/ou construindo. Para tanto, deve-se elaborar um minucioso projeto de desenvolvimento de produto para atender com qualidade, facilidade e agilidade tanto os requisitos técnicos quanto as demandas dos usuários.

Seguido deste capítulo de introdução, o capítulo 2 aborda a revisão da literatura sobre o Processo de Desenvolvimento do Produto (PDP). No capítulo 3 é apresentada a metodologia adotada. Em seguida, no capítulo 4, apresenta-se o desenvolvimento do projeto. Por fim, o capítulo 5 conclui o presente trabalho.

\section{Processo de desenvolvimento do produto}

Segundo Rozenfeld et al. (2006), o Processo de Desenvolvimento de Produto (PDP) consiste em realizar especificações de projeto e processos de produção de um produto, a partir das necessidades do mercado e condições tecnológicas que a manufatura possua, além de envolver o acompanhamento do produto mesmo após o lançamento, a fim de melhorias ou sua descontinuidade.

A partir de modelos referenciais de PDP, Rozenfeld et al. (2006) propuseram um modelo referencial dividido em três macro fases: pré-desenvolvimento, desenvolvimento e pósdesenvolvimento.

Na fase de pré-desenvolvimento há a definição de metas para empresa e como alcançá-las, são analisados: riscos de implementação, cronogramas, recursos humanos e financeiros relevantes para a implementação do projeto. Se ocorrer a viabilização do projeto e este for aprovado, então é elaborado o plano de projeto com a minuta dos produtos que serão desenvolvidos na fase de desenvolvimento (Rozenfeld et al., 2006).

A fase de desenvolvimento subdivide-se em projeto informacional, projeto conceitual, projeto detalhado, preparação do produto e lançamento do produto. No projeto informacional define-se os requisitos, metas e valores que o produto deve atender para atingir as exigências dos clientes (Rozenfeld et al., 2006).

No projeto conceitual são elaboradas as especificações do produto, tais como: croqui do produto, processos de fabricação que poderão ser utilizados, além da viabilidade econômica. Após escolha da melhor alternativa é iniciado o projeto detalhado, do qual é fabricado o protótipo, identificando falhas e efeitos (Rozenfeld et al., 2006). 
Tendo em vista a melhoria desta fase de desenvolvimento, pode-se utilizar a ferramenta Desdobramento da Função Qualidade (Quality Function Deployment -QFD) que é uma ferramenta de tradução dos requisitos do consumidor em características de qualidade para o produto, afetando diretamente a qualidade total do produto (Akao, 1990). Segundo Ribeiro et al. (2001), QFD é um método de gerenciamento solucionando os problemas questionados pelas perguntas: o que precisa ser feito e como pode ser feito. De acordo com Batista e Novais (2019), o QFD é uma das ferramentas mais viáveis para as empresas que desenvolvem produtos, pois ela auxilia a entender quais as necessidades que um cliente procura em um produto, além de analisar os produtos concorrentes disponíveis no mercado. Além do desenvolvimento de produtos, o QFD pode ser aplicado em diferentes assuntos, como a seleção de métricas de sustentabilidade para cadeia de suprimentos (Abdel-Basset et al., 2019) e para definir requisitos necessários para a aplicação da estratégia da modularidade nos fornecedores de primeiro nível do setor automotivo (Carnevalli et al., 2018).

Para a próxima fase, lançamento do produto, são definidas especificações de venda, marketing, distribuição e assistência técnica. E finalmente a macro fase de pós-desenvolvimento, a qual acompanhará os problemas e melhorias no produto em todo seu ciclo de vida (Rozenfeld et al., 2006).

Como o objetivo do produto será a produção de concreto, as variáveis do processo segundo a NBR 12655/2006 - "Concreto de cimento Portland - Preparo, controle e recebimento - Procedimento" as variáveis na dosagem do preparo do concreto são:

- Resistência do concreto (FcK): tem uma variação de acordo com o projeto estrutural, que deve respeitar a NBR 6118 - Projeto de Estruturas de Concreto, sendo cada resistência para um uso típico (cintas de amarração, fundação, pilares, vigas, lajes, etc). Unidade padrão: Mpa;

- Volume do concreto: quantidade de concreto necessário em $\mathrm{m}^{3}$;

- Abatimento (slump) do concreto: característica do concreto relacionada com viscosidade, fator água/cimento e resistência;

- Tipo de cimento: de acordo com a NBR 5732/91 - Cimento Portland existe no mercado cimento tipo I, II, III, IV e V. Cada um com sua particularidade e uso específico.

\section{Metodologia}

Este trabalho é uma pesquisa descritiva aplicada (Mascarenhas, 2012) e tem como instrumento estudo de caso (Gil, 2010) sobre desenvolvimento de um produto - aplicativo gratuito para celulares Android para quantificação de produção de concreto, tendo como base a bibliografia de desenvolvimento de produtos do modelo de Rozenfeld et al. (2006). Optou-se pelo método do Fluxograma para facilitar as diretrizes de todas as etapas do desenvolvimento do aplicativo. Aliou-se 
também o emprego de ferramentas como o QFD para descobrir-se as necessidades dos usuários que desencadeiam em características e qualidades específicas do produto em questão. Apresentando as etapas, metodologias e raciocínio empregado até a versão do produto, também foram demonstrados os resultados quantitativos do aplicativo na forma de número de downloads e nota efetuada pelos usuários finais na plataforma da loja virtual Google Play Store aonde se encontra disponível o aplicativo.

\section{Desenvolvimento}

Nesta seção foi apresentado o detalhamento das fases do desenvolvimento do produto, que são referentes ao projeto informacional, projeto conceitual, projeto detalhado e lançamento do produto.

\subsection{Projeto informacional}

Neste trabalho, o processo de concepção do produto foi iniciado já na fase de desenvolvimento, visto que todo contexto abordado na introdução já justifica a criação do aplicativo.

No projeto informacional geram-se diretrizes para posteriores etapas, as quais tiveram que ser tomadas decisões de métodos e opções a fim de garantir o melhor para o produto.

A primeira etapa do processo foi utilizar a ferramenta QFD respondendo as seguintes perguntas: O que? Para quem? Como? Por quê?

Baseando no atual cenário, para resolver sua problematização chegou as seguintes diretrizes básicas: confiabilidade dos resultados, facilidade de uso, público alvo diversificado, facilidade de desenvolvimento.

A confiabilidade dos resultados é o principal objetivo, pois é exatamente isso que o aplicativo visa combater, a compra incorreta, exacerbada e/ou incompleta de materiais.

O público alvo abrange engenheiros, construtores, pedreiros, lojistas da construção civil e leigos (donos de obras). Com essa grande heterogeneidade de usuários há maior relevância na escolha linguagem e informações para suprir as demandas de todos; o que também leva à necessidade de uma facilidade no uso do programa. Como o propósito da versão Lite (opção mais rápida, leve e que pode ser utilizada por celulares com baixo desempenho) do aplicativo é verificar se há demanda e ter o feedback dos usuários quanto a objetivos, desejos dentre outros, preferiu-se fornecer o aplicativo de forma gratuita. Sendo assim não é pertinente custos altos nesse aplicativo, portanto optou-se por uma fácil maneira de desenvolvimento de aplicativos sem a necessidade da contratação de um serviço especializado. 


\subsection{Projeto conceitual}

As escolhas das diretrizes encaminham o projeto conceitual, auxiliando no processo escolha e exclusão de alternativas para o melhor desenvolvimento de encontro com as metas a serem atingidas (Rozenfeld et al., 2006).

Nessa fase foi investigado o que seria necessário para atender as diretrizes do fluxograma da Figura 1.

Figura 1

Fluxograma processo preliminar

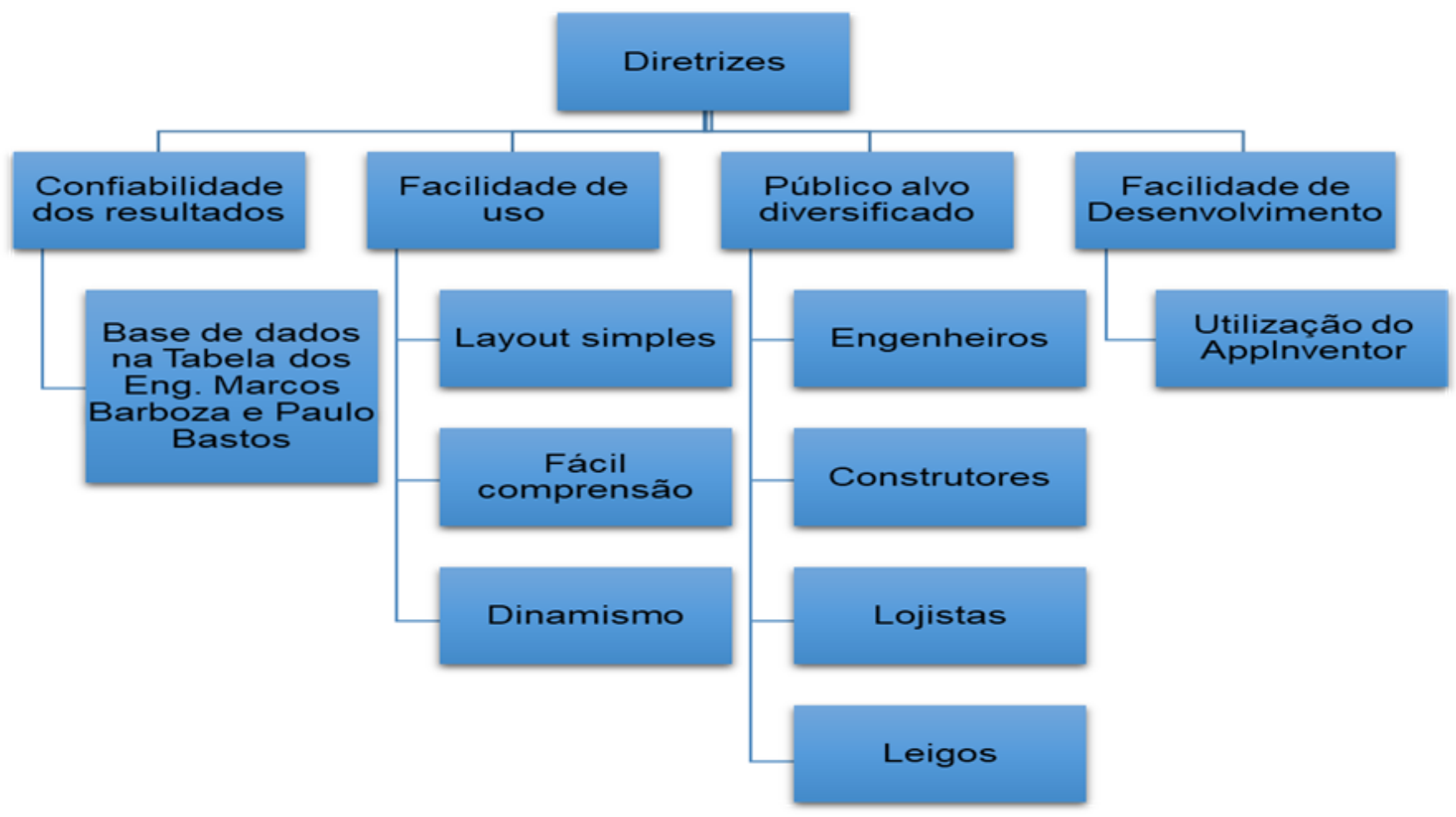

Fonte: Elaborado pelos autores.

Para a diretriz "Confiabilidade de Resultados", houve um estudo de inúmeras tabelas com traço de concretos, optou-se pela adoção da tabela de traços de concreto para obras de pequeno porte de Barboza e Bastos (2008), devido seu seguimento das normas técnicas vigentes, modo de abatimento de concreto usual de pequenas obras e esclarecimento de todos os parâmetros dos materiais usados, o que permite um grande grau de confiabilidade (Barboza; Bastos, 2008).

A fim de obter a diretriz "Facilidade de uso", é necessário atentar-se para um layout simples e objetivo, com poucas opções de escolhas e intuitivo; fácil compreensão do aplicativo; dinamismo, o usuário deve obter a quantificação de forma rápida. 
Para o desenvolvimento do aplicativo foi escolhida a plataforma Applnventor, visto que com pouco conhecimento de lógica de programação já é suficiente para conseguir produzir um aplicativo para o sistema operacional de smartphones Android. Além do fato de ser um ambiente para desenvolvimento gratuito, atinge justamente o sistema operacional mais utilizado, o Android, segundo relatório da Statcounter de 2017. O lado negativo dessa plataforma de desenvolvimento é que não é possível produzir uma versão para o sistema operacional do Iphone.

\subsection{Projeto detalhado}

No projeto detalhado o foco principal é a produção do protótipo. Para atingi-los há alguns processos a serem cumpridos. No caso deste trabalho, para concluir o desenvolvimento, faltam definir as variáveis de entrada e o layout do aplicativo.

Para definição das variáveis de entrada, foi realizado um QFD de diagrama de afinidades (Quadro 1) a fim de aprofundar as qualidades exigidas no fluxograma da Figura 1, depois integrá-los juntamente com as premissas na NBR 12655/2006 - "Concreto de cimento Portland - Preparo, controle e recebimento - Procedimento" para então definir as variáveis que o usuário poderá modificar e estruturar o layout sem perder as qualidades exigidas.

\section{Quadro 1}

\section{QFD Diagrama de Afinidades}

\begin{tabular}{|c|c|c|}
\hline Dados & Cenário & Qualidade Exigida \\
\hline \multirow{8}{*}{$\begin{array}{l}\text { Uso por } \\
\text { profissionais e } \\
\text { leigos }\end{array}$} & \multirow{5}{*}{ Profissionais } & Informar resistência (fck) \\
\hline & & Informar tipo de cimento \\
\hline & & Informar slump (abatimento) \\
\hline & & Informar propriedades dos materiais \\
\hline & & Informar traço em sacos e $\mathrm{m}^{3}$ \\
\hline & \multirow{3}{*}{ Leigos } & Informar uso indicado para cada resistência \\
\hline & & Informar traço em lata de $18 \mathrm{~L}$ \\
\hline & & Informar modo de usar \\
\hline \multirow{3}{*}{ Uso fácil } & Layout simples & Selecionar opção de Traço/fck(resistência) \\
\hline & Minimizar opções & Selecionar Traço, Volume \\
\hline & $\begin{array}{l}\text { Determinação do } \\
\text { Volume de Concreto }\end{array}$ & Opção de cálculo de volume ou somente informar valor \\
\hline
\end{tabular}

Com a integração do QFD do Quadro 1, o Fluxograma da Figura 1, mais as variáveis na NBR 12655/2006 descritas neste trabalho em Processo para Desenvolvimento do Produto definiu-se como variáveis de entrada, ou seja, os dados que usuários poderão alterar: a Resistência do concreto (Fck) e volume do concreto. Já para outras variáveis: abatimento (slump) e o tipo de cimento; optou-se por padronizá-las com valores de com o uso mais recorrente a fim de evitar confusões devido ao fato de 
nem todos os usuários terem total domínio técnico além de deixar o cálculo mais dinâmico. Em obras de pequeno-médio porte normalmente opta-se por um abatimento de $17 \mathrm{~cm}$, sendo este o valor utilizado pelo aplicativo.

O uso do cimento tipo II-E-32 é mais comercializado e empregado em todo Brasil, salvo poucas exceções, assim foi considerado este tipo de cimento, conforme as diretrizes estabelecidas por Barboza e Bastos (2008).

Depois, as atenções voltam para o layout. A conhecida importância do layout junto com a fácil compreensão para todo público e um rápido resultado culminou em difícil tarefa. Após muitas tentativas, optou-se por dar aos usuários múltiplas opções fixas para determinação da resistência do concreto (fck), as resistências mais usuais. Como nem todos consumidores conhecem a usabilidade da resistência do concreto, em cada opção também será fornecida a aplicabilidade e o traço (proporção de material - muito utilizado por pedreiros, construtores).

Outro dado a ser preenchido pelo usuário será o volume de concreto desejado. A fim de deixar mais versátil, há duas opções, a de volume conhecido, em que já conhece a quantidade de concreto então resta somente informar o valor em $\mathrm{m}^{3}$; e a outra, em que o aplicativo calcula a quantidade de volume, a partir de dados de largura, comprimento, profundidade e quantidade de "peças" que o cliente deve preencher.

Para atender a diversidade de público, o resultado do cálculo será apresentado no consumo de cimento em $\mathrm{Kg}$ e saco de cimento de $50 \mathrm{Kg}$, areia e brita em $\mathrm{m}^{3}$, água e aditivo em Litros. Não haverá nenhuma porcentagem de acréscimo na quantidade de materiais por conta de desperdício, mas terá uma mensagem aconselhando tal acréscimo. O programa também fornecerá o Rendimento por saco de cimento de concreto em $\mathrm{m}^{3}$, litros e latas de 18 litros e o traço para um saco de cimento.

Para informar mais sobre o método de cálculo, propriedades consideradas dos materiais, foi criada uma aba "Sobre", contendo todas essas informações técnicas.

Optou-se por demonstrar o modo de usar do aplicativo na própria loja virtual, assim o futuro usuário já consegue perceber a facilidade e acaba sendo mais um atrativo para download.

Após a fase avaliação e melhoramento, começou literalmente a ser esboçado o layout do aplicativo. Percebeu-se a necessidade de ter um pequeno menu, dando possibilidades de mais informações e também já o campo de argamassa para a possível próxima versão.

Solucionado o layout, o funcionamento final do aplicativo segue então o seguinte esquema:

1. Selecionar um box com o traço, FcK (resistência), uso indicado do concreto;

2. Apertar o botão volume, selecionar entre: 'calcular volume' e 'volume conhecido';

3. Para a opção 'calcular volume', fornecer: comprimento, largura, altura em metros e quantidade de peças a serem concretadas; 
4. Para a opção 'volume conhecido', digitar o valor de concreto em metros cúbicos;

5. Selecionar o botão 'calcular';

6. O aplicativo fornecerá quantidade de areia, brita e cimento para produzir o volume de concreto desejado.

Após a versão final do aplicativo, foram feitos testes de uso no aplicativo para descobrir falhas de programação e verificação dos cálculos apresentados. Estes foram identificados, corrigidos e passados novamente por mais uma etapa de testes.

\subsection{Lançamento do produto}

Para o lançamento do aplicativo foi utilizado o QFD (Quadro 2) abrangendo as atividades de Valor de Venda, Distribuição, Marketing, Assistência Técnica.

\section{Quadro 2}

QFD Lançamento.

\begin{tabular}{l|l}
\hline Atividade & Forma Escolhida \\
\hline Valor Venda & Gratuito \\
\hline Distribuição & Google Play Store (loja virtual) \\
\hline Marketing & E-mail de engenheiros / lojista / profissionais da ICC \\
\hline Assistência Técnica & Via e-mail \\
\hline
\end{tabular}

Fonte: Elaborado pelos autores.

O valor de venda será nulo, para investigação da demanda de clientes interessados no assunto de quantificação de material para a construção civil. A distribuição foi realizada pela loja virtual do Google Play Store, com o nome de Traço Lite. Foi escolhida a Google Play Store por ser a loja instalada de fábrica nos aparelhos celulares com sistema operacional Android. A ação de Marketing foi simplória visando a não alocação de recursos financeiros. Houve uma divulgação via e-mail para 50 engenheiros e informalmente para pessoas ligadas a construção civil, construtores e pedreiros.

O canal de comunicação com o cliente e a assistência técnica escolhida foi via e-mail divulgado no próprio aplicativo e no portal da loja virtual Play Store.

\subsection{Pós lançamento - resultados}

Mesmo com a baixa ação de marketing, a quantidade de instalações mostrou uma grande evolução como pode ser conferida no Quadro 3 - Quantidade de instalações por período. 


\section{Quadro 3}

Quantidade de instalações por período.

\begin{tabular}{|l|r|}
\hline Período & Quantidade de Instalações \\
\hline Outubro 2014 - Dezembro 2014 & 124 \\
\hline Janeiro 2015 - Dezembro 2015 & 5.774 \\
\hline Janeiro 2016 - Dezembro 2016 & 13.558 \\
\hline Janeiro 2017 - Novembro 2017 & 5.403 \\
\hline Total até Novembro 2017 & $\mathbf{2 4 . 8 5 9}$ \\
\hline
\end{tabular}

Fonte: Elaborado pelos autores.

Pode-se avaliar que o produto foi bem sucedido a partir dos retornos quantitativos e qualitativos. Assim, para o resultado quantitativo pode-se usar o número total de downloads atual, novembro de 2017 (24.859 downloads). Resultado sem ação de marketing apenas com a demanda natural do mercado, o que demonstra que há mercado para este produto. Na perspectiva qualitativa será utilizada como referência sua avaliação média pelo usuário na própria loja virtual (Play Store). Sua avaliação atual é de 4,34 (conceito de 0 - 5), demonstrando que o usuário possui satisfação e confiança pelo produto. Soma-se ainda, o fato de inúmeros pedidos via e-mail ou por comentário na loja virtual solicitando a versão Pro, além dos elogios ao produto.

\section{Considerações finais}

Conclui-se que a aplicação do conhecimento do processo de desenvolvimento de um produto, em especial o modelo referencial de Rozenfeld et al. (2006), aborda diversas questões em cada etapa, sendo uma ótima ferramenta para garantir um produto final de qualidade e que atenda as especificações técnicas e operacionais dos clientes, podendo assim atingir o sucesso desse. Lembrando que o modelo é um referencial, este deve sofrer modificações e individualizações de acordo com o segmento do produto e da empresa.

Pode-se concluir que o desenvolvimento do aplicativo nomeado de Traço Lite foi bem sucedido em seu propósito principal e secundário. A finalidade principal de ser uma ferramenta fácil e rápida para mensuração de materiais necessários para obtenção de concreto obteve um feedback positivo do abrangente público-alvo, tanto quantitativamente quanto no aspecto qualitativo. Obtendo mais de 20.000 downloads e nota de avaliação de 4,34 (0 - 5) pelos usuários.

Também obteve uma resposta positiva em sua finalidade secundária que é de mensuração e resposta do mercado para lançamento de um aplicativo mais abrangente no âmbito de mensuração de materiais para construção civil e este sim com objetivo de lucro financeiro atrás da venda do aplicativo.

Com o resultado da adesão dos usuários ao aplicativo Traço Lite associado ao contexto de falta de qualidade técnica para quantificação e especificação de materiais da construção civil aliado ainda 
com a massificação do uso de aparelhos smartphones, conclui-se que é viável o emprego de recursos financeiros para desenvolvimento de outro aplicativo mais completo e abrangente para mensuração de materiais da construção civil, enfatizando ainda que o desenvolvimento de aplicativos técnicos é um mercado pouco explorado.

\section{Referências}

Abdel-Basset, M., Mohamed, R., Zaied, A. E. H., \& Smarandache, F. (2019). A Hybrid Plithogenic Decision-Making Approach with Quality Function Deployment for Selecting Supply Chain Sustainability Metrics. Symmetry, v. 11, n. 7. Doi: https://doi.org/10.3390/sym11070903

Akao, Y. (1990). Quality Function Deployment: Integrating Customer Requirements into Product Design. Boston: Productivity Press.

Associação brasileira de normas técnicas. (1991). NBR 5732: Cimento Portland Comum. Rio de Janeiro.

Associação brasileira de normas técnicas. (2006). NBR 12655: Concreto de cimento Portland - Preparo, controle e recebimento - Procedimento. Rio de Janeiro.

Associação brasileira de normas técnicas. (2003). NBR 6118: Projeto de estruturas de concreto Procedimento. Rio de Janeiro.

Barboza, M. R. \& Bastos, P. S. (2008). Traços de Concreto para Obras de Pequeno Porte. UNESP, Bauru.

Bastos, P. S. (2005). Vigas e Lajes de Concreto Armado. UNESP, Bauru.

Batista, D. S. \& Novais, J. W. Z (2019). A Aplicação da Gestão da Qualidade no Desenvolvimento de Novos Produtos: o Uso do Desdobramento da Função de Qualidade (QFD). Ensaios e Ciência, v. 23, n.1, p. 7-11. Doi: http://dx.doi.org/10.17921/1415-6938.2019v23n1p7-11

Carnevalli, J. A., Sousa, J. E. R., Benedicto, S. C., Medeiros, C. G. A., \& Georges, M. R. R. (2018). Uso do QFD para definir requisitos necessários para a aplicação da estratégia da modularidade nos fornecedores de primeiro nível do setor automotivo. Exacta, São Paulo, v. 16, n. 4, p. 149-163. out./dez. 2018. Doi: https://doi.org/10.5585/ExactaEP.v16n4.7426

Cheng, L. C. (1995). QFD: Planejamento da Qualidade. Belo Horizonte: UFMG/Fundação Christiano Ottoni.

Cheng, L. C. \& Melo Filho, L. D. R. (2007). QFD: Desdobramento da Função Qualidade na Gestão de Desenvolvimento de Produtos. São Paulo: Blucher.

Dallasega, P., Rauch, E., \& Linder, C. (2018). Industry 4.0 as an enabler of proximity for construction supply chains: A systematic literature review. Computers in Industry, v. 99, p. 205-225. Doi: https://doi.org/10.1016/j.compind.2018.03.039

de Carvalho, J. M., Melo, T. V. D., Fontes, W. C., Batista, J. O. D. S., Brigolini, G. J., \& Peixoto, R. A. F. (2019). More eco-efficient concrete: An approach on optimization in the production and use of waste-based supplementary cementing materials. Construction and Building Materials, v. 206, p. 397-409. Doi: https://doi.org/10.1016/j.conbuildmat.2019.02.054 
Giongo, J. S. (2007). Concreto Armado: Projeto Estrutural de Edifícios. USP, São Carlos.

GIL, A. C. Como elaborar projetos de pesquisa. 5a ed. São Paulo: Atlas, 2010. p. 32

Judina, A. (2020). Non-reagent methods for the activation of concrete mix raw components in the construction industry. Architecture and Engineering, v. 5, n. 1, p. 30-35. Doi: https://doi.org/10.23968/2500-0055-2020-5-1-30-35

Mascarenhas, S. A. Metodologia científica. São Paulo: Pearson, 2012. p. 45 e 47

Rozenfeld, H.; Forcellini, F.; Amaral, D. C.; Toledo, J.; Alliprandini, D.; Silva, S. L. E.; Scalice, R. K. (2006). Gestão de Desenvolvimento de Produto: Uma Referência para Melhoria do Processo. São Paulo: Saraiva.

Ribeiro, J. L. D; Echeveste, M. E.; Danilevicz a. M. F. (2000). A Utilização do QFD na Otimização de Produtos, Processos e Serviços. Porto Alegre: UFRGS.

Santos, R. E. (2008). A armação do concreto no Brasil: história da difusão do sistema construtivo concreto armado e da construção de sua hegemonia, Brasil, Tese (Doutorado em Educação) Faculdade de Educação, Universidade Federal de Minas Gerais, Belo Horizonte.

Souza, U.E. L; Paliari, J. C.; Agopyan, V.; Andrade, A. C. (2004). Diagnóstico e combate à geração de resíduos na produção de obras de construção de edifícios: uma abordagem progressiva. Ambiente Contruído, Porto Alegre, v. 4, n. 4, p. 33-46, out./dez. 